Bangladesh J. Sci. Res. 26(1\&2): 11-19, 2013 (December)

\title{
PRIORATIZATION OF VILLAGES FOR PROVIDING SAFE WATER SOURCES IN DISASTER PRONE SARANKHOLA UPAZILA OF BAGERHAT DISTRICT: A GIS BASED APPROACH
}

\author{
Sarmin Sultana*, Md. Badrul Alam and Kazi Matin Ahmed \\ Department of Geology, Faculty of Earth and Environmental Sciences, \\ University of Dhaka, Dhaka-1000, Bangladesh
}

\begin{abstract}
Sarankhola Upazila of Bagerhat district is one of the most water scarce and disaster prone areas of the country. Village level map of existing safe water options for this Upazila has been prepared using data on number of water supply technologies for each village using ArcGIS 9.1. Hydrometeorological, geological and hydrogeological data have been analyzed to decipher the geohydro-environment in order to validate site specific water supply options. Existence of different safe water options in every village alongside population density has been presented in the map in order to identify high, medium and low priority areas. It is evident from the analysis that where shallow tubewell is less successful, the safe water coverage is also low. Rainwater harvesting is the least used option despite having high annual rainfall and therefore, can be used in large numbers along with pond sand filter (PSF) in order to improve safe water coverage. Results obtained from the study can be utilized as a planning tool to optimize the safe water coverage by targeting priority areas. The map also identifies the areas suitable for a particular safe water option and can be used as a guiding tool for installing the appropriate sustainable safe water options during future interventions.
\end{abstract}

Key words: Water scarcity, GIS, priority villages, safe water options

\section{Introduction}

The coastal areas of Bangladesh are at great risk of climatic change and sea level rise because of its geographic location and low elevation. As surface water is mostly brackish or saline, water access in the coastal area depends on availability of fresh groundwater. Fresh groundwater occurrence in Sarankhola is very rare and the local population has to rely on limited freshwater ponds and seasonal rainwater. Again these fresh water ponds have been severely affected by cyclones Sidr and Aila and many areas have become permanently water logged. Also intentional flooding of lands by brackish water for shrimp cultivation makes the inhabitants of the area more vulnerable in terms of fresh water access. As rainwater is not available throughout the year the scarcity of fresh water is severe during dry period. A good number of water supply technologies are available for installation in rural areas of Bangladesh. However, most options are area specific depending on local hydrogeological environments. Safe water supply option like shallow tube well (STW), pond sand filter (PSF), shrouded shallow tube well (SST), very shallow

*Corresponding author: <sarmin@du.ac.bd>. 
shrouded tube well (VSST) and rainwater harvesting (RWH) are widely used in the coastal regions and elsewhere in the country (DPHE/JICA 2008). In some villages of Sarankhola, there are good numbers of STW and those villages essentially are not water scarce. Some villages exclusively depend on rain and fresh water ponds due to lack of shallow groundwater and there is severe water scarcity in those areas in the dry season. However, a small number of villages use both surface and groundwater where access is better. Therefore, a systematic village scales GIS mapping of existing safe water options can provide a clearer view of the current water access scenario in Sarankhola Upazila which would help in identifying village with severe water scarcity needing interventions for improving access to safe water.

Study area: Sarankhola is situated in the southwestern coastal zone of Bagerhat district in Bangladesh having direct influence of tropical cyclones and having area of $756.61 \mathrm{sq} \mathrm{km}$ (Banglapedia 2003) (Fig. 1). Total population of Sarankhola Upazila is around 1, 25,000 (BBS 2008) and comprises of four Unions named Dhansagar, Khontakata, Rayenda and Dakshinkhali which includes 48 villages. It is bordered by the Chandpai river on the west and the Baleshwar river on the east and the Sundarban is in south.

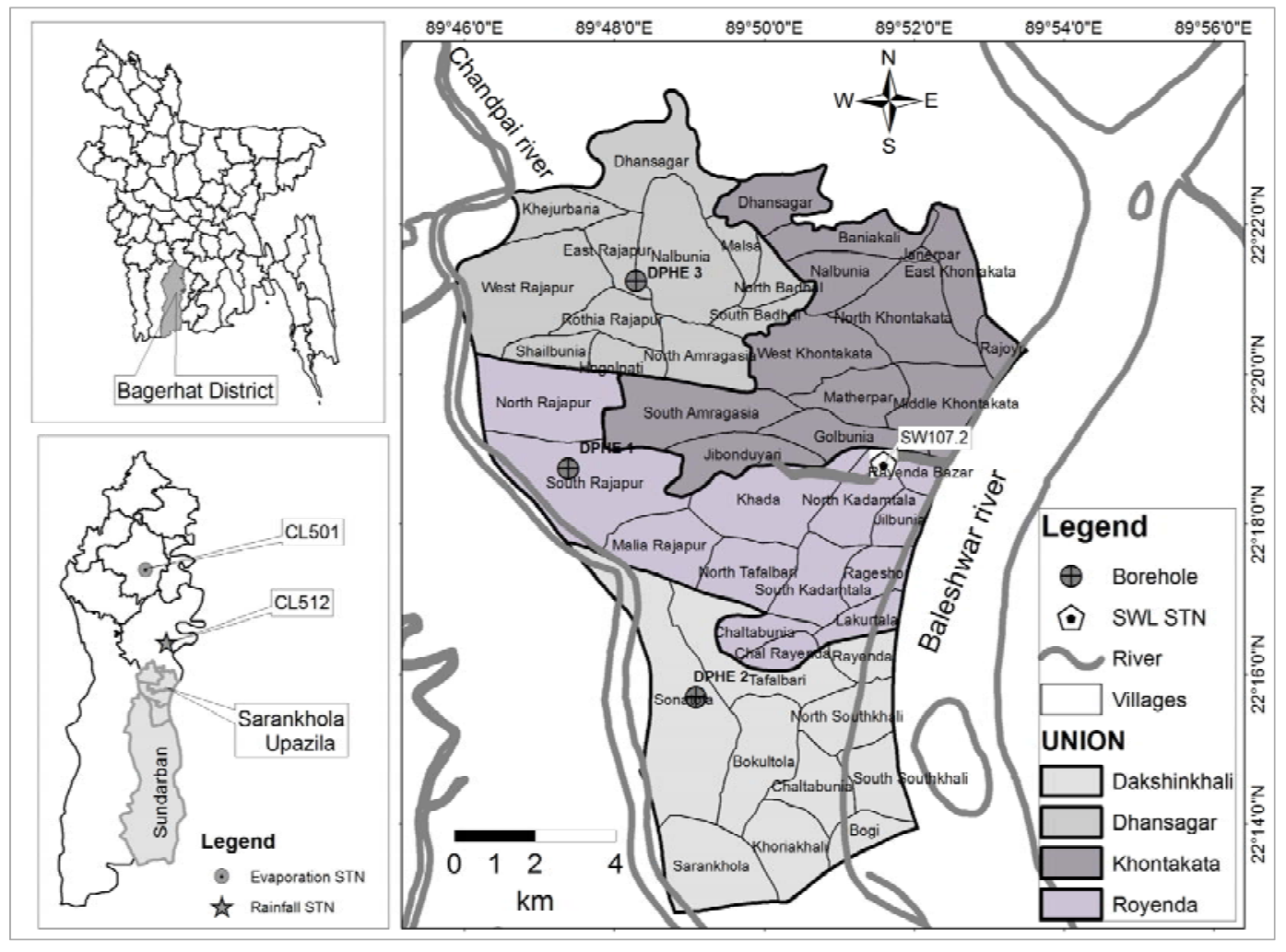

Fig. 1. Map of the study area showing borehole locations, surface water level monitoring station (SWL STN), rainfall and evaporation monitoring station. 


\section{Materials and Methods}

Long term daily data on surface water level (1987 to 2005) for the Rayenda station (SW 107.2) for the Baleswar River and weekly data on ground water level (1986 to 2005) for the nearest Mollahat observation well (GT0156004) has been collected from Bangladesh Water Development Board (BWDB) to construct long term hydrographs. Also daily rainfall data (1990 to 2006) for the nearest monitoring station CL512 located in Morrelganj and daily evaporation data (2004 to 2006) for the nearest station CL501 located in Bagerhat has also been collected from BWDB. Subsurface hydrostratigraphy of the area has been mapped based on lithologic information of Department of Public Health and Engineering (DPHE) to a depth of about $1100 \mathrm{ft}$. Fig. 1 shows location of all hydrometeorological monitoring stations and boreholes. Also latest village level data on different safe water options such as STW, DTW, PSF, SST, VSST, RWH and current population for Sarankhola Upazila has been collected from the DPHE along with hard copy of inaccurate maps of various water supply options at village levels.

Data of different safe water options have been entered into a simple database format using MS Access. ArcGIS 9.1 has been used and the base polygon shape file was created using the existing mouza layer (LGED 2006) available at the RS and GIS laboratory of the Department of Geology, University of Dhaka. The most common error encountered during the shape file generation process was to assign the boundary of newly created village not present in the existing shape files. To overcome this problem mouza shape files have been updated from the satellite image and DPHE manual map. The database created in MS Access was then linked with the newly created village shape file. Data was checked for consistency and gaps were identified using editor tool in GIS environment as it provided visual display on maps and discrepancies were easier to detect. The GIS analysis involved overlay operation and extensive use of programmed query analysis and manipulation.

\section{Results and Discussions}

The south central coastal Bangladesh is characterized by a very gentle sloping surface and is composed of sediments carried by the Ganges-Brahmaputra river systems to the Bay of Bengal since long geologic past (Alam 1997). Islam and Tooley (1999) described coastal sedimentary layers as the natural archives of coastal processes, sea level, water level and water quality changes. The study area comprises of a $400 \mathrm{~m}$ thick sequence of Quaternary sediments overlying the MioPliocene sequence. The upper 30 to 70 meter of the geological profile is of Holocene age and consists of unconsolidated sand, silt and clay with occasional peat and the remaining deposits belong to the Pleistocene or older ages (Goodbred et al. 2000).

The long term water level hydrograph for the Baleswar river shows that the study area is strongly affected by the tidal wave, which reaches up to $3.5 \mathrm{~m}$ above mean sea level (MSL) during high tide goes below the MSL during low tide (Fig. 2b). A long term average of total monthly rainfall bar diagram and evaporation line curve has been constructed (Fig. 3a). From the figure it has been observed that monthly distribution of both rainfall and evaporation is non uniform 
throughout the year. Most of the rainfall occurs during monsoon from May to October with significant pre-monsoon rainfall occurring during March and April; there is very little or no rainfall during the dry period from November to February.

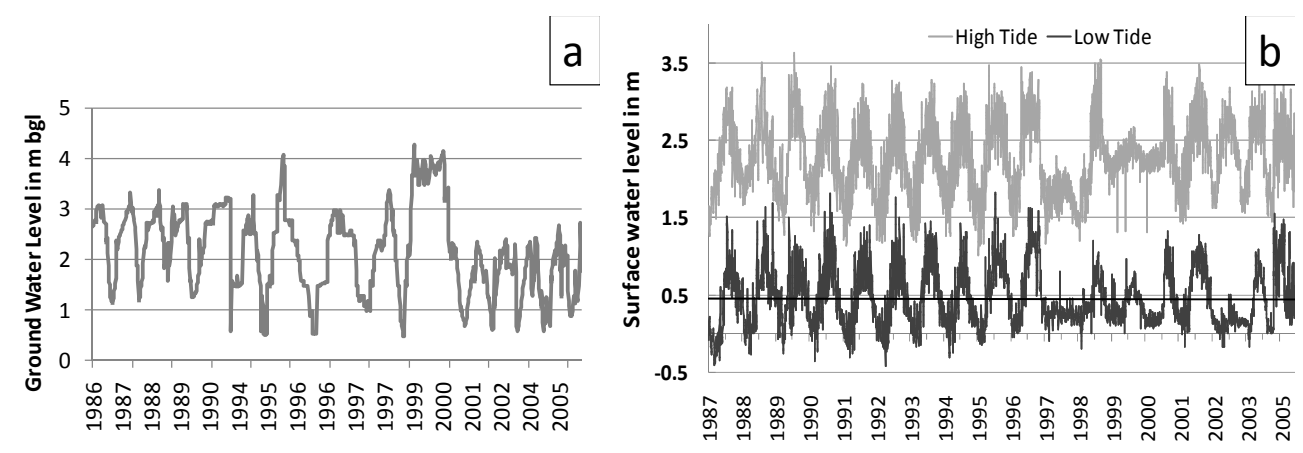

Fig. 2. Long term hydrograph of (a) ground water level below ground surface and (b) surface water level fluctuation curve (Data source BWDB).

The graph also shows maximum evaporation occurs in April which is about $175 \mathrm{~mm}$ and minimum in July which is about $50 \mathrm{~mm}$. Climatic surplus occurs from May to October where rainfall is much higher than evaporation and people can rely on rainwater during this period for potable uses by harvesting rainwater; on the other hand climatic stress period occurs from November to April where evaporation is higher than rainfall and people suffers from extreme crisis of potable water during this time.
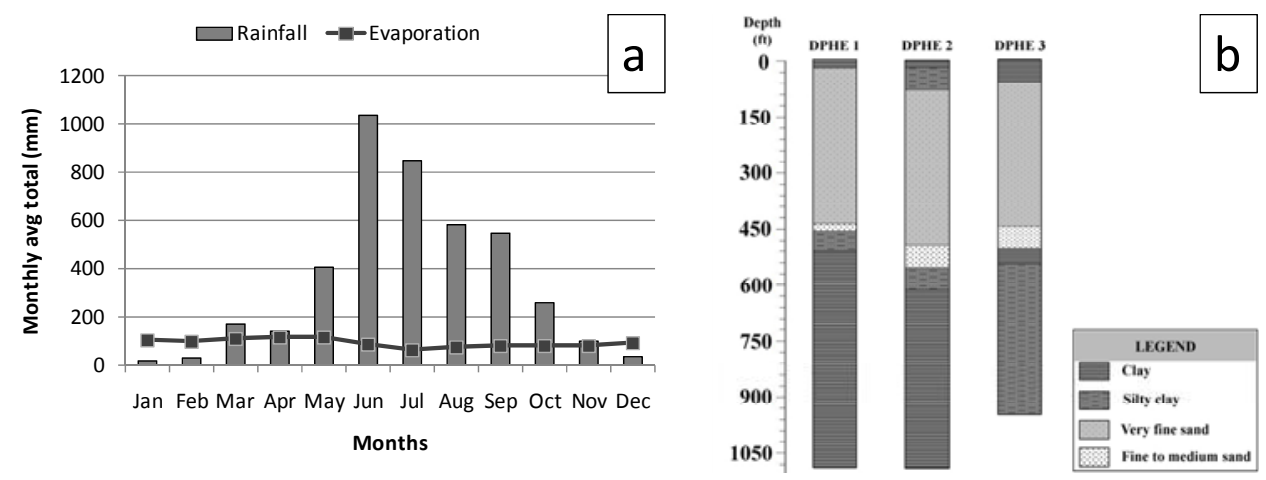

Fig. 3. (a) Long term monthly average rainfall and evaporation distribution curve (data source BWDB), (b) Lithologs at the study area (data source DPHE).

Only three lithologs of exploratory drillings up to a depth of $1100 \mathrm{ft}$ were available with DPHE for Sarankhola Upazila and fresh water aquifer was not encountered at any of the locations. By analyzing all the bore logs four lithologic viz. clay, silty clay, very fine sand and fine to medium sand have been identified (Fig. 3b). Only one aquifer can be identified from the bore logs which are termed as the shallow aquifer. The aquifer consists of very fine sand with subordinate 
fine to medium sand with thickness reaching up to $500 \mathrm{ft}$ and is found in almost all bore logs with a clay aquitard on the top. Unlike many other parts of the coastal area no deep aquifer is encountered here up to the drilled depth of $1100 \mathrm{ft}$ as the entire sequence underneath the shallow aquifer consists of clay and silt (Fig. 3b). Ground water level hydrograph does not show any significant long term trend and a seasonal influence is clearly seen as the ground water level reaches near the surface (only $0.5 \mathrm{~m}$ below the ground level) during rainy season and declines to more than $4 \mathrm{~m}$ from the surface during the dry season (Fig. 2a). The shallow aquifer of the area contains brackish ground water which is not potable as demonstrated by electrical conductivity (salinity) values of limited existing shallow hand tube wells. At the Amragachia village of Dhanshagor Union EC varies from 5.5 to $6.5 \mathrm{mS} / \mathrm{cm}$ at 21 feet whereas at Rajoir village of Khontakata Union EC varies from 6.0 to $7.5 \mathrm{mS} / \mathrm{cm}$ at $50 \mathrm{ft}$ which are not potable according to Bangladesh drinking water standard (MoEF 1997).

Village level maps of existing STW, SST and VSST, PSF and RWH with different class based on the number have been produced as shown in Fig. 4a, b, c and d). Most villages of Dhansagor Union show occurrence of minimum numbers of STW, SST and VSST indicating unsuitability of the area for further ground water development. The scenario of Khontakata and Rayenda Union is opposite as a good number of STW are present and there is potentials to develop more ground water based safe water options in these two unions due to presence of shallow fresh ground water pockets although the significant variation in number of existing SST and VSST decipher a patchy nature of shallow ground water occurrence. Also there is good coverage of safe water through PSF in these two unions compared to other, making these two unions less priority area. The safe water coverage of Dakshinkhali union is also good as significant number of STWs is present along with PSF and SST. However, three villages of the union do not have any safe water option making those villages high priority areas for future interventions. Of the existing safe water options, RWH is the least used one despite high seasonal rainfall. The number and distribution existing PSF indicate that this can become a safe water option in a good number of villages. Therefore, installation of a good number of PSF and RWH can improve the safe water coverage significantly in the high priority areas. For each village statistics of existing safe water options is presented in the map with the help of pie diagram (Fig. 5a). In order to identify the priority areas, comparison of current population per village with the number of existing safe water option has been made in order to get the population lacking adequate coverage of safe water supply. For this first a population map with three different categories has been produced (Fig. 5b). From the GIS analysis it is identified that among 48 villages, 28 villages have population in the range of 2000 to 5000 showing moderate population density. Only a small proportion of the Upazila is densely populated where more than 10,000 people are found in two villages each which are Sarankhola in Dakshinkhali Union and Matherpar in Khontakata Union. Remaining 18 villages have low population density with less than 2000 people living in each village. Table 1 provides the information on how many people can be served by a safe water option. 

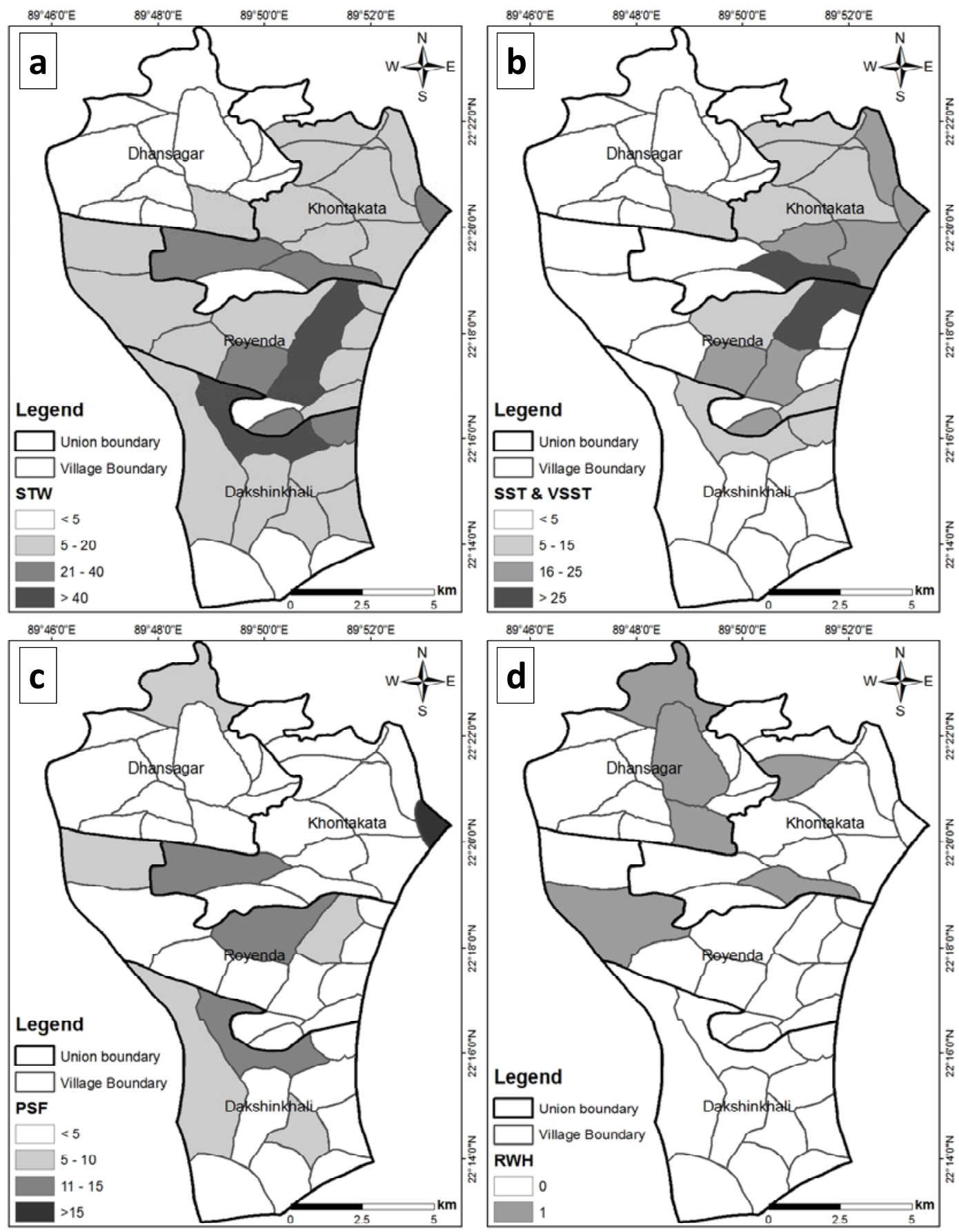

Fig. 4. Village wise distribution of existing (a) STW, (b) SST and VSST, (c) PSF and (d) RWH in four Unions of Sarankhola Upazila. 
Table 1. Number of people served by different types of safe water options (Source: JICA/DPHE 2010).

\begin{tabular}{lcc}
\hline Type of safe water option & $\begin{array}{c}\text { No. of family that can be } \\
\text { served }\end{array}$ & $\begin{array}{c}\text { No. of people that can be } \\
\text { served (5 per family) }\end{array}$ \\
\hline Pond sand filter (PSF) & 18 & 90 \\
Shallow tubewell (STW) & 13 & 65 \\
Shallow shrouded tubewell (SST) & 4 & 20 \\
Very shallow shrouded tubewell (VSST) & 4 & 20 \\
Rain water harvester (RWH) & 1 & 5 \\
\hline
\end{tabular}

The number of people in an individual village having safe water coverage has been calculated against the number of existing STW, SST, VSST, PSF and RWH in that particular village. Population in need of safe water coverage has been estimated by subtracting the population having safe water coverage from the total population of that village. Three different types of priority villages for providing safe water were identified following the classification shown in Table 2 and Fig. 5b. From GIS analysis it is found that only 8 villages fall in the category of

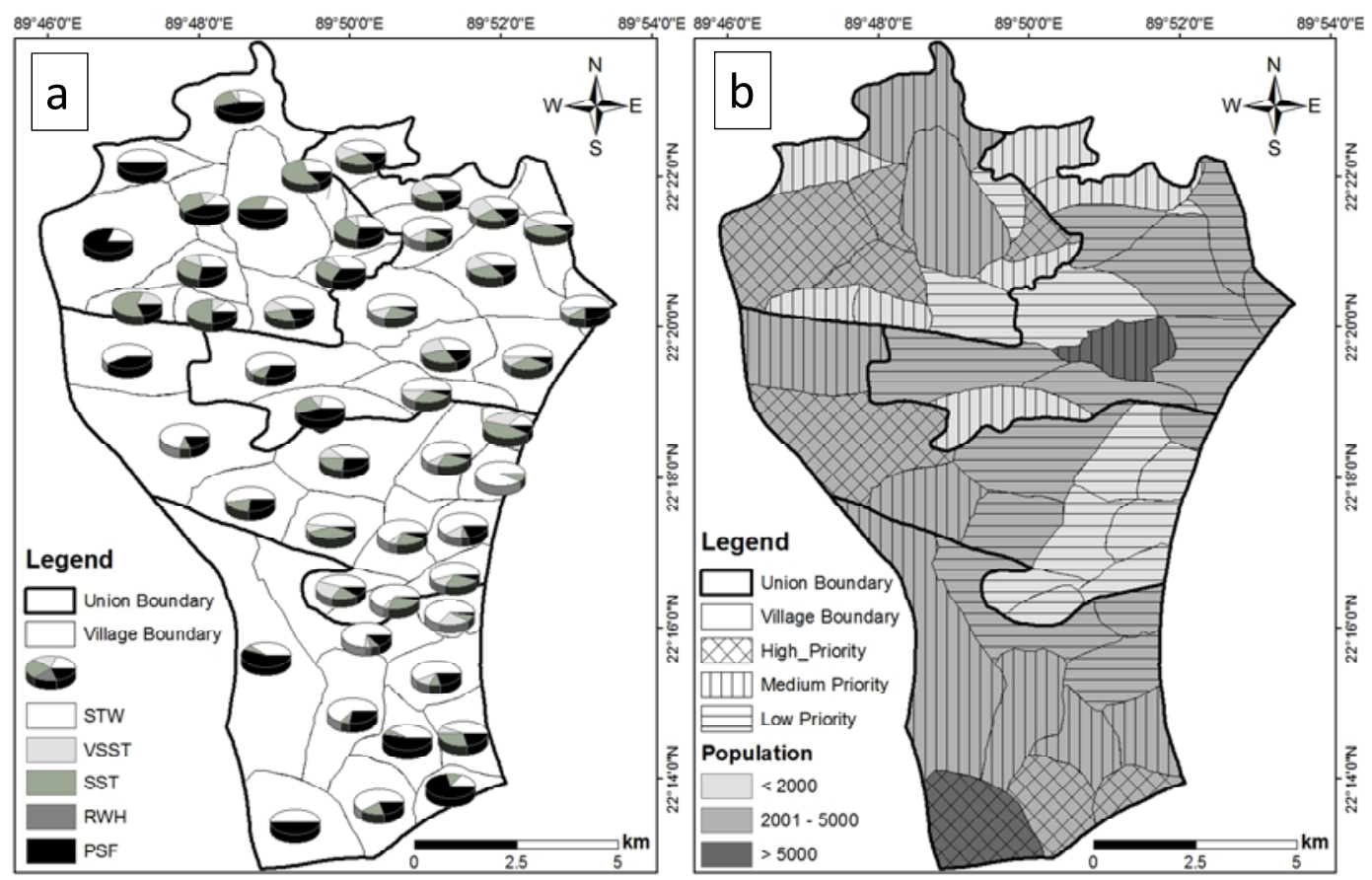

Fig. 5. (a) Spatial distribution of different safe water option existed in each village by pie diagram and (b) village wise distribution of population of Sarankhola Upazila with the overlay of three different classes of priority villages.

high priority area where there is a large gap between total population and population having safe water coverage. A considerable gap is found in the medium priority area which comprises of 16 villages whereas no significant gap has been found in low priority area comprising of 24 villages (Fig. 6). 
Table 2. Three classes of priority villages based on population not served by safe water.

\begin{tabular}{lc}
\hline Name of the Class & Percentage of people unserved \\
\hline High priority & $>75$ \\
Medium priority & $\geq 50$ to $<75$ \\
Low priority & $<50$ \\
\hline
\end{tabular}

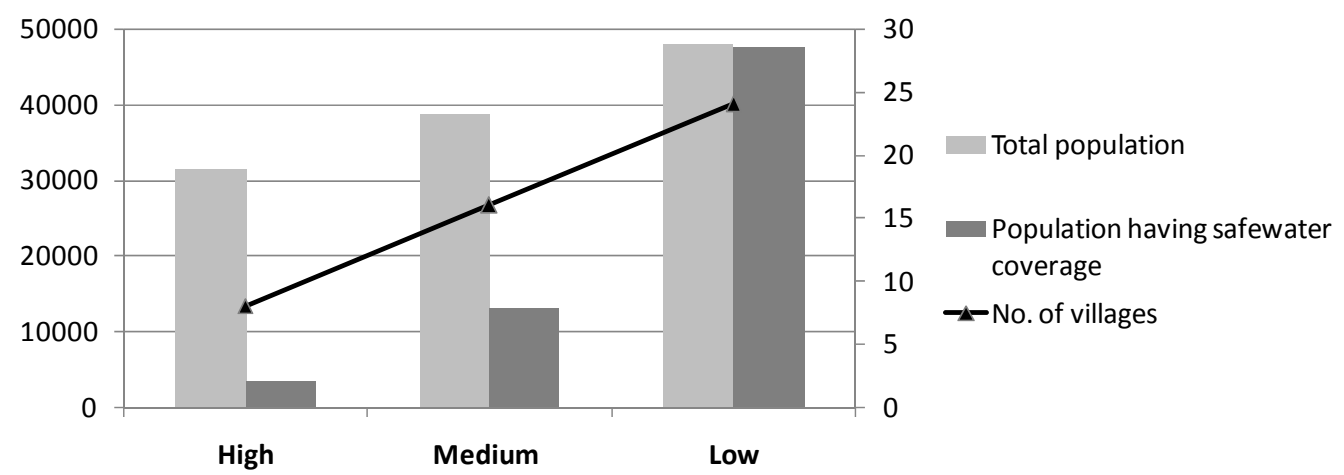

Fig. 6. Distribution of total population and population having safe water coverage at three different priority areas with the number of villages in each.

\section{Conclusions}

Sarankhola Upazila of Bagerhat district in the south-western coastal belt of Bangladesh is one of the worst affected areas by cyclone Sidr and Aila and still today a large population is suffering from safe water scarcity. Village level mapping of existing safe water options in this Upazila has been carried out which shows many of the villages are unsuitable with respect to hydrogeology for developing shallow tube wells. It is clear that where STW is less successful, the safe water coverage is also low. Under such circumstances, it is important to use other water supply technologies to provide safe water. Rainwater harvesting is the least used option among the existing technologies and therefore a good number of rainwater harvesting can be built in order to improve safe water coverage although this option is not suitable for the dry season. Existence of a good number of PSF indicates the availability of suitable ponds which can be used as the source for this option. The PSFs are also at risk because of likely impacts of cyclonic storms like Sidr and Aila. Therefore, it is important to find safe and sustainable water supply technology for this area. Population served different safe water options in every village against total population has been presented in the map and the priority areas for intervention have been identified. Results obtained from the current study should be considered to increase the safe water coverage by targeting the high priority areas. It has been found from the study that all options are not equally suitable for all unions; rather the technologies are area specific and it is important to provide area specific safe water options. 
The current study is based on the DPHE data and did not consider the water supply options installed by different NGOs and individuals. The outcome of the study would have been more useful and meaningful if it was possible to incorporate all of the existing water supply options operational in the area. It may not be possible to improve the current water supply coverage using only the currently used options. Innovative technologies are required to increase safe water coverage as well as to protect the existing fresh surface water storage from inundation during storm surges.

\section{References}

Alam, M. 1996. Subsidence of the Ganges - Brahmaputra Delta of Bangladesh and Associated Drainage, Sedimentation and Salinity Problems. In: J.D. Milliman and B.U. Huq (eds.) Sea-level rise and coastal subsidence, Coastal Systems and Continental Margins 2: 169-192.

Banglapedia - The National Encyclopedia of Bangladesh. 2003. 9: 71-72, Asiatic Society of Bangladesh.

BBS, 2008. Bangladesh Bureau of Statistics, Census 2008.

DPHE/JICA, 2008. Report on Evaluation of the Performance, Village Piped Water Supply System (120 Schemes). Groundwater Circle, Department of Public Health and Engineering, Dhaka.

Goodbred, Jr., S.L. and Kuehl, S.A. 2000. Enormous Ganges - Brahmaputra sediment load during strengthened early Holocene monsoon. Geology 28: 1083-1086.

Islam, M.S. and Tooley M.J. 1999. Coastal and sea-level changes during the Holocene in Bangladesh. Quaternary International. 55: 61- 75.

JICA/DPHE. 2010. Situation Analysis of Arsenic Mitigation, Department of Public Health Engineering and Japan International Cooperation agency, Final Report, 2010.

LGED. 2006. Local Government Engineering Department, Government of the People's Republic of Bangladesh, 2006.

MoEF. 1997. Ministry of Environment and Forest, Government of Bangladesh, Water Quality Standards for Drinking and Irrigation by Gazette Notification in 1997, Government of the People's Republic of Bangladesh.

(Manuscript received on 14 March, 2013; revised on 30 March, 2013) 